\title{
A case of necrotizing fasciitis due to Klebsiella following local application of steroids
}

\author{
Suhaib Rehaman Abdul', Robin George ${ }^{2}$ \\ ${ }^{1}$ Consultant - Surgeon, Department of Surgery, ${ }^{2}$ Consultant - Physician, Department of Medicine, National Hospital, \\ Calicut, Kerala, India
}

Klebsiella organisms are known to cause a spectrum of clinical syndromes in human beings which include pneumonia, urinary tract infection, abdominal infection, surgical site infection, soft tissue infection and infection of intravascular devices. The incidence is higher among immunocompromised individuals and those with chronic debilitating diseases like diabetes, alcoholism etc. We present an elderly diabetic male who developed necrotizing fasciitis of the leg following local application of steroids. The causative organism turned out to be Klebsiella, which is an unusual pathogen.Moreover, necrotizing fasciitis due to Kleibsella in

\section{Access this article online}

Website:

http://nepjol.info/index.php/AJMS

DOI: 10.3126/ajms.v7i6.15429

E-ISSN: 2091-0576

P-ISSN: 2467-9100 the absence of other infectious foci is a rare scenario.

Key words: Nectrotizing fasciitis, Klebsiella, Steroids

\section{INTRODUCTION}

Klebsiella organisms can cause bacteraemia, especially in diabetic and immunocompromised individuals. Among the spectrum of clinical syndromes, pneumonia, urinary tract infection and hepatic abscess account for $15-30 \%$; infections of intravascular devices as $5-10 \%$; and the remaining is seen as surgical site infections or as miscellaneous infections.

Necrotizing fasciitis (NF) is a life-threatening infection of the soft tissue, characterised by rapidly progressive necrosis of the subcutaneous tissue and superficial fascia. ${ }^{2}$ Previously, it was called streptococcal gangrene, as group A Streptococcus was the leading cause of monomicrobial NF. Other organisms include MRSA strains, Clostridium perfringens and mixed aerobic-anaerobic bacteria. ${ }^{3}$ The occurrence of Klebsiella as the sole pathogen of $\mathrm{NF}$ is rather uncommon. It is usually associated with predisposing conditions like diabetes mellitus or may occur as disseminated lesions from other infectious sites. ${ }^{4}$

The case being reported is of a diabetic patient with chronic eczema who presented with acute NF of left leg following local application of steroids. Klebsiella being the causative organism is rather uncommom, especially in the absence of other infectious foci.

\section{CASE REPORT}

Our patient is a 65 year old male, who presented to the Emergency department with complaints of high grade fever with left lower limb swelling and tenderness. He is a diabetic for the past 10 years on glimepiride and metformin. He is also a known case of chronic eczema for which he has been applying topical steroids (beclomethasone) as advised by a Dermatologist (Figure 1).

He was symptomatic for the past 2 days. He initially noticed mild redness over the anterior aspect of his left lower limb, for which he consulted a local practioner and was started on oral cefuroxime. The same night he had applied beclomethasone cream (which he usually uses for his eczema lesions) over the area of redness. The next day morning, he developed fever and noticed that the swelling had increased, involving the entire left lower limb, which 
had also become fully erythematous. He also had difficulty in walking because of limb pain.

On examination, he was conscious, oriented and febrile with temperature of $102^{\circ} \mathrm{F}$. His heart rate was 100 beats/minute which was regular, blood pressure of $100 / 70 \mathrm{mmHg}$ and respiratory rate of $20 /$ minute with $96 \%$ oxygen saturation in room air. Local examination of left lower limb revealed erythema and oedema extending up to the knee, with local rise in temperature. There were multiple blebs over the medial aspect of the limb, just above the medial malleolus. His systemic examinations were normal. On the basis of his history and examination findings, a provisional diagnosis of advanced cellulitis with NF was made.

His initial laboratory investigations showed anaemia $(\mathrm{Hb}$ $11.0 \mathrm{~g} / \mathrm{dl})$ and elevated leucocyte count $(23,000$ cells $/ \mathrm{cmm})$ with differential counts as N90 L8 E2. His renal functions were mildly deranged with urea of $60 \mathrm{mg} / \mathrm{dL}$ and creatinine $1.4 \mathrm{mg} / \mathrm{dL}$. Serum electrolytes, liver function tests and PT/INR were normal. His random blood sugar was $275 \mathrm{mg} / \mathrm{dL}$ and urine ketones were negative. His ECG and chest Xray were normal. Ultrasound study of left lower limb was suggestive of cellulitis with NF and no evidence of deep vein thrombosis. Ultrasound abdomen was normal.

He was taken up for emergency fasciotomy and debridement under short general anaesthesia. Lay opening was done at the dorsum of the foot with both medial and lateral side fasciotomy (Figures 2-4). The pus fluid and tissue fascia were send for culture, which grew Klebsiella. He was started on Piperacillin + Tazobactam and Clindamycin (which were also sensitive as per antibiotic sensitivity reports). Daily dressings were done. His sugar levels were controlled with insulin. By day 3, his vitals were stable. His total counts reduced to 12,000 cells $/ \mathrm{cmm}$ and renal parameters became normal with urea 38 and creatinine $1.2 \mathrm{mg} / \mathrm{dL}$. A redebridement was done for the necrotic patch on the medial side of the limb and all the skin and subcutaneous tissue were excised. Secondary suturing was done over the dorsum of the foot and lateral side of the limb. The intervention on the medial side was delayed for the granulation tissue to occur. He was later taken up for split thickness skin grafting with graft taken from the medial side of the left thigh. His postoperative stay in hospital was uneventful and was discharged on day 12 of admission with regular follow up.

\section{DISCUSSION}

Klebsiella, a gram negative bacilli, has become an emerging cause for community-acquired and nosocomial infections.

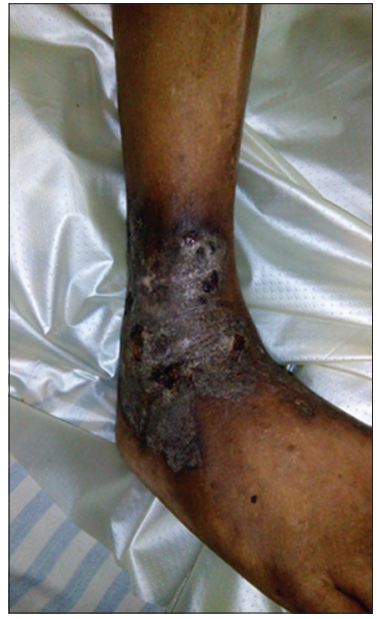

Figure 1: Chronic eczematous lesion over lower limb

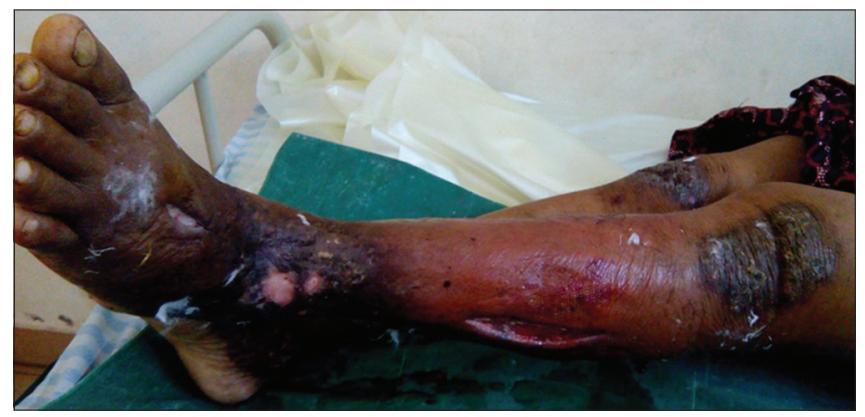

Figure 2: NF of left lower limb - Post fasiotomy and debridement

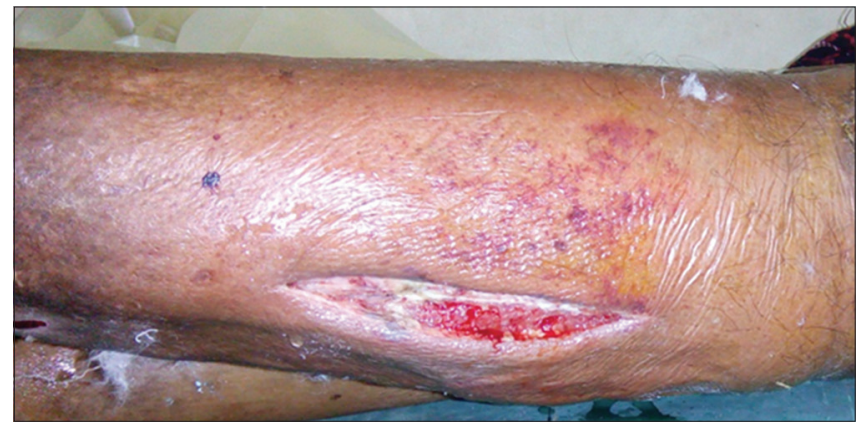

Figure 3: Lateral aspect

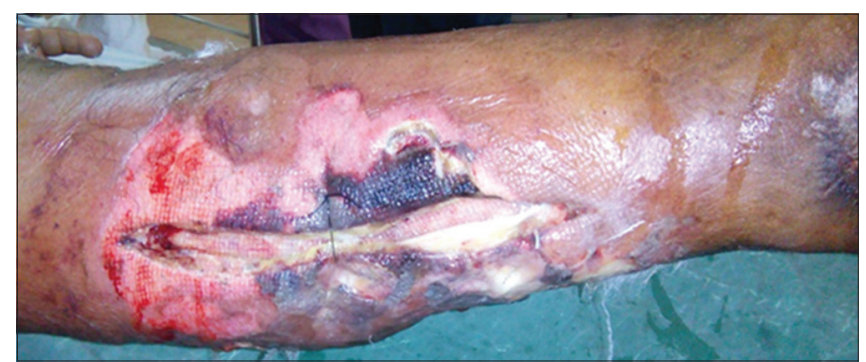

Figure 4: Medial aspect

Higher incidence has been reported among diabetic patients. ${ }^{5,6}$ These organisms cause soft tissue infection either by gaining direct access from an injured site, or from other septic foci via haematogenous route. 
Klebsiella, as a monomicrobial cause of NF, is an uncommon presentation. There have been a few reports of such cases, but they were all associated with other foci of sepsis, commonly liver abscesses, urinary tract infections and endogenous endophthalmitis. Therefore, it is always essential to look for other infectious foci in cases of soft tissue infections due to Klebsiella. ${ }^{5,7,8}$ In a single hospital study conducted in Taiwan, Klebsiella was found to be responsible for $17 \%$ of monomicrobial NF, and held a higher mortality rate. Moreover, $80 \%$ of these patients were diabetic. ${ }^{9} \mathrm{~A}$ few fatal cases of Klebsiella NF have been reported from North America. ${ }^{10}$ Interestingly, the cases of Klebsiella were more common among Asian population and those of Asian descent, hence raising the possibility of genetic susceptibility in these infections. ${ }^{11}$

$\mathrm{NF}$ is a surgical emergency, requiring debridement until tissue necrosis ceases and fresh viable tissue growth is seen. ${ }^{12}$ Daily antibiotic dressings are essential. ${ }^{13}$ Soft tissue reconstruction can be considered once all of the affected tissues have been debrided. Antibiotic administration, especially broad spectrum, is a key consideration. The emergence of resistant strains is another major concern, warranting combination of antimicrobial therapy. ${ }^{1}$ Other modalities like hyperbaric oxygen therapy (HBOT) may be considered as an adjuvant therapy. ${ }^{14}$

\section{CONCLUSION}

In this case, the patient is a diabetic and a known case of chronic eczema on treatment with topical steroids. He developed mild cellulitis of leg for which he was started on oral cephalosporin. However, due to the emergence of resistant strains of Klebsiella, cephalosporin was insufficient to tackle the infection. The situation was further worsened by the unsupervised application of topical steroids, thereby leading to NF. Klebsiella as a monomicrobial cause of NF, in the absence of other septic foci, still remains an uncommon presentation; and to the best of our knowledge, an acute development of NF (over a period of few hours) from cellulitis following topical steroid application has not been reported yet.

\section{REFERENCES}

1. Thomas AR and James RJ. Diseases caused by gram-negative enteric bacilli. In: Kasper, Fauci, Hauser, Longo, Jameson, Loscalzo (ed). Harrison's Principles of Internal Medicine. $19^{\text {th }}$ ed. McGraw Hill education. pp. 1031-1033.

2. Wong $\mathrm{CH}$, Chang HC, Pasupathy S, Khin LW, Tan JL and Low CO. Necrotizing fasciitis: clinical presentation, microbiology and determinants of mortality. J Bone Joint Surg Am 2003; 85$A(8): 1454-1460$.

3. Stevens DL. Infections of the skin, muscles, and soft tissues. In: Kasper, Fauci, Hauser, Longo, Jameson, Loscalzo (ed). Harrison's Principles of Internal Medicine. 19 ${ }^{\text {th }}$ ed. McGraw Hill education. pp. 1031-1033.

4. Hu BS, Lau YJ, Shi ZY and Lin YH. Necrotizing fasciitis associated with Klebsiellapneumoniae liver abscess. Clin Infect Dis 29:1360-1361.

5. Lye WC, Chan RK, Lee EJ and Kumarasinghe G. Urinary tract infections in patients with diabetes mellitus. J Infect 1992; 24(2):169-174.

6. Chang CM, Lee HC, Lee NY, Lee IW, Wu CJ, Chen PL, et al. Community-acquired Klebsiellapneumoniae complicated skin and soft-tissue infections of extremities: emphasis on cirrhotic patients and gas formation. Infection 2008; 36:328-334.

7. Hu BS, Lau YJ, Shi ZY and Lin YH. Necrotizing fasciitis associated with Klebsiella pneumoniae liver abscess. Clin Infect Dis 1999; 29:1360-1361.

8. Ho PL, Tang WM and Yuen KY. Klebsiella pneumonia necrotizing fasciitis associated with diabetes and liver cirrhosis. Clin Infect Dis 2000;30(6): 989-990.

9. Cheng NC, Yu YC, Tai HC, Hsueh PR, Chang SC, Lai SY, et al. Recent trend of necrotizing fasciitis in Taiwan: Focus on monomicrobial Klebsiella pneumoniae necrotizing fasciitis. Clin Infect Dis 2012;55:930-939.

10. Rana MM, Sturdevant M, Patel G and Huprikar S. Klebsiella necrotizing soft tissues infections in liver transplant recipients: a case series. Transpl Infect Dis 2013;15:157-163.

11. Shon AS, Bajwa $R$ and Russo TA. Hypervirulent (hypermucoviscous) Klebsiellapneumoniae: a new and dangerous breed. Virulence2013;4:107-118.

12. Wang $\mathrm{KC}$ and Shih $\mathrm{CH}$. Necrotizing fasciitis of the extremities. J Trauma 1992; 32(2):179-182.

13. Gear AJ, Hellewell TB, Wright HR, Mazzarese PM, Arnold PB, Rodeheaver GT, et al. A new silver sulfadiazine water soluble gel. Burns 1997; 23(5):387-391.

14. Riseman JA, Zamboni WA, Curtis A, Graham DR, Konrad HR and Ross DS. Hyperbaric oxygen therapy for necrotizing fasciitis reduces mortality and the need for debridements. Surgery 1990; 108(5):847-850.

\section{Authors Contribution:}

SRA - Treating surgeon; RG - Concept and design of case report, reviewed the literature, manuscript preparation and critical revision of manuscript; and corresponding author, treating physician.

Source of Support: Nil, Conflict of Interest: None declared. 